\title{
Combined immunodeficiency with faciooculoskeletal anomalies
}

INSERM

\section{Source}

INSERM. (1999). Orphanet: an online rare disease and orphan drug data base. Combined immunodeficiency with faciooculoskeletal anomalies. ORPHA:221139

Combined immunodeficiency with faciooculoskeletal anomalies is an extremely rare combined immunodeficiency disorder characterized by primary immunodeficiency manifesting with repeated bacterial, viral and fungal infections, in association with neurological manifestations (hypotonia, cerebellar ataxia, myoclonic seizures), developmental delay, optic atrophy, facial dysmorphism (high forehead, hypoplastic supraorbital ridges, palpebral edema, hypertelorism, flat nasal bridge, broad nasal root and tip, anteverted nares, thin lower lip overlapped by upper lip, square chin) and skeletal anomalies (short metacarpals/metatarsals with cone-shaped epiphyses, osteopenia). 